\title{
Supply Management Governance Role in Supply Chain Risk Management and Sustainability
}

\author{
Reham Eltantawy \\ Marketing and Logistics Department, \\ Coggin College of Business, \\ University of North Florida \\ USA
}

\section{Introduction}

Supply chains face increased pressure from stakeholders to incorporate a plethora of corporate responsibility and sustainability aspects in their constituents' business practices. Legal and extra-legal demands are dynamically changing; almost no industry, supply chain, organization, and an organizational function are unaffected. Owing to the outsourcing wave of the last decade (Reuter et al., 2010), in particular purchasing and supply management (PSM) plays an ever more important role in assuring sustainable supply chains in the marketplace.

In order to manage supply chain risks, supply management must ensure that their local and international practices and relationships comply with their stakeholders' expected codes of conduct and that environmental and social misconducts do not occur, while maintaining profitability. The proposed framework (Figure 1) highlights the "dynamic nature" of requisite supply management capabilities and governance mechanisms. This is mainly due to the need to creating a strategic fit between supply chains and the continually changing supply chain risks. This strategic fit denotes "supply chain resilience;" defined as "the capacity for a supply chain to survive, adapt, and grow in the face of turbulent change" (Pettit et al., 2010). Resilient supply chains are proposed to require certain forms of supply management governance, i.e., structures and processes intended to coordinate and integrate various dimensions of supply management. Governance represents the structures and processes by which supply chain constituents share power, also shapes individual and collective actions (Young, 1992).

Despite interest, there is clear dearth of research on the nature of supply management's role in sustainability. It would be of great insight to the supply management field to explore "What are the supply management capabilities and governance mechanisms used to sustain a supply chain?" This conceptual study contributes to prior research in the fields of SM and supply chain sustainability by extending insights of the resilience and capabilities view to analyze how SM governance integrates sustainability aspects in its supply chain practices.

This conceptual study responds to the need for well coordinated efforts that draw on established theories concerning supply chain's sustainability. Building a supply chain sustainability theory offers not just scholarly but also practical value (Ketchen and Hult, 2011). 
This study aims at generating and presenting the sustainable supply chain theory by introducing the concept of ecological resilience. The proposed framework is grounded in the resilience perspective, which is increasingly applied to the study of the dynamics of socialecological systems (Folke, 2006). This perspective offers an integrative view that permits understanding, managing, and governing complex linked systems of people and institutions. Introducing ecological resilience implies a developmental process that involves grafting this new concept onto the existing structure of sustainable supply chain theory in a way that shifts attention to new opportunities without overtly challenging entrenched positions (Skilton, 2011). With introducing this new concept to a recently heavily researched theory, along with pertinent new proposed relationships and the realignment of existing ones, a more parsimonious logical structure of sustainable supply chain theory is sought. The main goal is to excite these essentially aesthetic sensibilities other scholars about the proposed framework and its falsification, and thereby extend the life of the proposed theory.

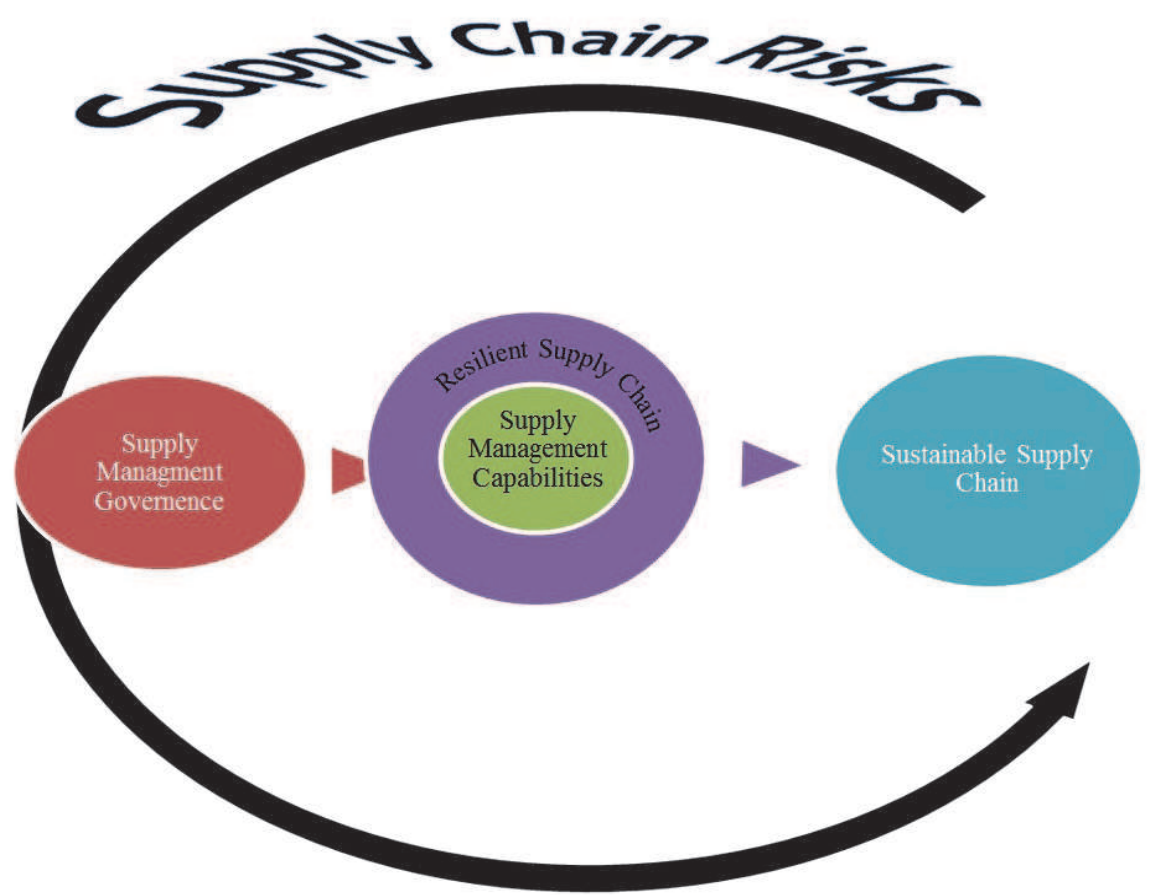

Fig. 1. Framework of Supply Management Governance, Supply Chain Risks, and Sustainability

On the one hand, over the last decade, the bulk of research that uses resilience has linked it to ecology. Unlike the supply chain phenomenon, where social-ecological systems cannot be tightly controlled and independently manipulated, most of the work in building the resilience theory is based on controlled experiments and classical scientific approaches conducted under highly reduced and controlled conditions. This study seeks to extend the resilience theory to supply chain; a context that parallels the natural ecosystems that the ecological resilience theory is intended to explain. This in itself will enrich the resilience 
theory and its applications. On the other hand, the study aims at using a broad interdisciplinary view on "sustainable supply chain" as a phenomenon by adding to the growing body of concepts of this young research strand. To accomplish this goal, it uses an interdisciplinary approach by drawing insights from ecology, economics, marketing, social science, strategy and, supply chain literatures to begin an interdisciplinary assessment of the ideas developed in previous works regarding resilience in interlinked systems of people and ecosystems, with expansions into some areas of supply chain

This study contributes to practice by crystallizing the requisite SM governance and capabilities to supply chain sustainability. These capabilities are path dependent and particularly valuable when supply chains and their constituent members are risk aware and receptive to external stakeholder pressures. Early movers in the field of resilient and sustainable supply chains are expected to reap competitive benefits to a notable extent as a result of resource accumulation and learning processes over time. The following section discusses the literature review and theoretical background of the proposed framework, then proposed relationships are presented and managerial implications are discussed.

\section{Theoretical background and literature review}

A supply chain is generally conceptualized as a network of companies from suppliers to end-users, which have the intention of integrating supply/demand via coordinated company efforts (Frankel et al., 2008). Supply chains are complex and linked socialecological systems of people and institutions. The concept of resilience in supply chains combines these previous tenets with studies of supply chain vulnerability, defined by Svensson (2002) as "unexpected deviations from the norm and their negative consequences." Vulnerability can be measured and expressed in numeric terms as "risk", a combination of the likelihood of an event and its potential severity (Craighead et al., 2007; Sheffi 2005). Both these definitions have foundations in traditional risk management techniques and are expanded by other authors (Svensson, 2002; Zsidisin, 2003; Pettit et al., 2010).

The concept of resilience is used extensively in engineering, ecological sciences, and organizational research, all of which provide insight into creating a conceptual framework for supply chain resilience. In the ecological sciences, the standard definition of resilience is "the ability for an ecosystem to rebound from a disturbance while maintaining diversity, integrity, and ecological processes" (Folke, 2006). It may be beneficial for a supply chain not to return to its original "shape" following a disruption, but rather to learn from the disturbance and adapt into a new configuration (Pettit et al., 2010). Network theory views a supply chain as an adaptable living system and a resilient supply chain, therefore, should be efficient, adaptable, and cohesive (Fiksel, 2003). A resilient supply chain enjoys high levels of collaborations required to identify and manage risks where the culture of risk management is a necessity.

\subsection{Supply chain risks}

The escalating interest in sustainable supply chains is driven by a number of factors. Drawing from the literature on sustainable supply chains management (SCM) and green SCM, the drivers are classified into (Mann et al., 2010): (1) external to business, i.e., legislation and environmental drivers and (2) internal to the business, i.e., financial' drivers, internal business process drivers and the drivers related to the customer. These drivers represent sources of risks to a supply chain that have the potential to degrade a supply chain's operating condition and, thereby, it's economic, environmental and/or social 
performance outcomes. When the conditions of an ecosystem, a supply chain in this case, degrade to the extent to which it experiences attritions of its constituent members (i.e. individual firms), it transforms into an inferior and different regime.

On the one hand, this degradation may be drastic and sudden due to the very nature of supply chain phenomenon that causes vulnerabilities and risks. Uncertainties and nonlinearities in a supply chain often arise from both complex internal feedbacks and from interactions with structures and processes operating at other scales (Gunderson and Holling, 2002). Individual firms' expert knowledge is, therefore, incomplete and biased within a supply chain domain. Petit et al. (2010) referred to a recent example that demonstrates the importance of sudden instantaneous disruptions to the automotive manufacturing supply chain: "In 2007, a magnitude 6.8 earthquake in central Japan severely damaged the facilities of Riken Corp., a supplier of automobile components including specialized piston rings. Riken had located all of its plants in a single area of Japan to increase efficiency, making the entire production capacity vulnerable to a catastrophic incident. Earthquake damage to Riken facilities and its utilities completely shut down production for one week, and required another week of repairs to return to full output. As a result of carrying limited inventories, Toyota, one of Riken's many customers, was highly vulnerable to production and transportation disruptions. Toyota's sourcing strategy emphasized close relationships with a limited number of suppliers, but in this case Toyota was forced to shut down all 12 of its domestic assembly plants, delaying production of approximately 55,000 vehicles."

On the other hand, supply chain degradation might very well occur over a period of time that spans several business generations due to market imperfections (i.e., inefficient firms, externalities, flawed pricing mechanisms and information asymmetries) that contribute to environmental degradation and disruptions of supply chains wellbeing (Cohen and Winn, 2007). Ford, another auto maker, reported that the nature of their supply chain is that the big auto parts makers, or Tier 1 companies, rely on hundreds of lower-tier companies. For example, steel from a Tier 4 supplier is sent to a Tier 3-forging company that cuts it into pieces that are sent to a Tier 2 supplier that machines them into gears. The gears are sold to the Tier 1 transmission maker who supplies the finished gearbox to an automaker. Failure at any of these levels can stop an assembly line. The intertwined relationships rely on the final customer, the automaker, being financially stable and able to pay the bills. This is a scenario where social reputation risks and economic risks were intertwined over an extended period of time. The attrition rate in the supply chain has been 5 percent to 10 percent with about 40 major bankruptcies in 2008, many of them progressing rapidly from Chapter 11 to liquidation, said Dave Andrea, OESA's vice president of industry analysis and economics. With attrition, there are too many suppliers, and failure to shrink the supply base in an orderly fashion means it will occur in a more painful way, said Tony Brown, Ford group vice president of global purchasing.

A literature review of the topic in prominent SCM journals reflects the magnification of the role that supply management has been playing in risk management over the past decade. Supply chain management encompasses the planning and management of all activities involved in sourcing and procurement, conversion, and all logistics management activities. Importantly, it also includes coordination and collaboration with channel partners, which can be suppliers, intermediaries, third-party service providers, and customers. In essence, supply chain management integrates supply and demand management within and across companies" (Frankel et al., 2008). The outcomes of risk management varied in literature from resource efficiency, economic and social responsibility. Notably, more recently these outcomes became more encompassing and drove attention to "supply chain sustainability." 
Most of the recent discussions of sustainability are driven by the basic notion that a supply chain's performance should be measured not just by profits, but also by the impact of the chain on ecological and social systems (Pagell and $\mathrm{Wu}, 2009$ ). Supply management literature describes and measures supply chain inclusive wealth (wellbeing) in this sense on the basis of three components (triple bottom line): the natural environment, society, and economic performance; triple bottom line performance (Carter and Rogers, 2008).

The concept of "sustainability" has recently received noticeable attention from supply management researchers and practitioners (e.g., Krause et al., 2009; Pagell and Wu, 2009; Petit et al., 2010 and Pullman et al., 2009). Calls have been proposed that sustainability and its components represent an addition to the traditional set of competitive priorities for supply management. Kruase et al. (2009) proposed that, in addition to quality, cost, delivery, flexibility and innovation, sustainability must be addressed by each company as a competitive priority that should be manifested, in part, through the supply management practices, such as supplier selection and retention decisions. Nevertheless, supply management students and researchers seem to emphasize the minimization of cost and risk (Krause at al., 2009). This dual emphasis may be suboptimal when sustainability is an important competitive priority. There is lack of clarity when it comes to the role of supply management in capturing that duality; profitability while sustainable.

Guinepero and Eltantawy (2004) posited supplier management processes and relationships are the most susceptible link in a supply chain. An overview of supply management sustainability literature reveals, however, supply management research rarely addresses multidimensionality of its own susceptibility; economic, environmental, and social risks. Supply management governance mechanisms geared to capture economic goals may often times came at odds with social and/or environmental risk management goals and vice versa. The goal at this point is to instill the mechanisms that would minimize and allow tradeoffs when needed in ordered to sustain supply chain.

\subsection{Supply chain sustainability: Tradeoffs}

Consideration to the concept of sustainability is increasingly found in the management literature. An increase in publishing frequency of about 3/1000 to 15/1000 articles, over the period under consideration. (Linton et al, 2007). Sustainability, in essence, entails the maintenance of the productive base of an economy (i.e., supply chain) relative to its population (i.e., individual firms). Supply chain sustainability is a dynamic state influenced by two dichotomies: the supply chain versus the determinants of individual firm wellbeing, and current versus sustainable wellbeing (Cash, 2006). Accordingly, sustainability involves both a cross-sectional dimension and a temporal dimension. A supply chain enjoys sustainability if and only if: (1) relative to its firms, its inclusive wealth (economic, environmental, and social) does not decline (cross-sectional dimension), and (2), the supply chain could sustain its wellbeing (economic, environmental, and social) across business generations (temporal dimension).

Supply management literature largely defines sustainability as the tripartite pursuit of economic, environmental, and social performance, which is also referred to as the triple bottom line of the organization (e.g., Kleindorfer et al., 2005; Carter and Rogers, 2008; Reuter et al., 2010). In essence; "to be truly sustainable a supply chain would at worst do (1) no net harm to natural or social systems while still producing a profit (2) over an extended period of time; a truly sustainable supply chain could, (3) customer willing, continue to do business forever (Pagell 
and $\mathrm{Wu}, 2009) . "$ The role of supply management is complex: the three aspects of sustainable supply chains are at odds many cases and tradeoffs are important.

The first aspect of the expected tradeoff (1); doing no net harm at a profit. Doing no harm to the natural or social systems usually comes at the expense of producing profit. Procter \& Gamble (P\&G), the manufacturer of Pampers disposable diapers, is actively involved with sales-improving socially responsible practices such as infant life-saving health programs and education. However, $P \& G$ downplays environmental practices that conflict with their cost objectives (Pullman et al., 2009). Here, the reputational risks minimized were at odds with economic goal. In the same study, the authors reported that when analyzing Wal-Mart's recent sustainability report and metrics, they admit that their environmental sustainability efforts, e.g., environmental goals of 100 percent renewable energy, zero waste and products that sustain natural resources and the environment, are in alignment with cost savings for the firm, suppliers and customers. However, their social sustainability indicators are lacking, implying that those particular practices are not in alignment with cost savings.

The second set of tradeoffs (2); to do no harm at profit for an extended period of time. This may be untenable, unworkable and beyond reach in many cases. This is where there is a tradeoff between long-term vs. short term economic sustainability. Supply management students and researchers seem to emphasize the maximization of profit and minimization of cost and risk - this dual emphasis may be suboptimal when sustainability is an important competitive priority (Krause at al., 2009). Lean supply chains research and practice were driven by profit maximization and cost minimization goals. On the one hand, lean production may be conducive to environmental responsibility because it propagates the attainment of productivity goals using minimal inventory. The term is usually associated with the 1970s "just-in-time (JIT)" tactics of Toyota's assembly plants. In the 1990s, the term "lean" replaced JIT to emphasize the true objective of the philosophy: the elimination of waste throughout the supply chain (Jeffers, 2010). On the other hand, lean practices leave firms and supply chains vulnerable to risks and disruptions. In this case, the pursued economic sustainability; via lean practices, may impair other sustainability aspects and in some case mere survival goal when sudden interruptions to the supply chain take place. The 8.9 magnitude quake and ensuing tsunami of 2011 in Japan destroyed infrastructure and knocked out factories supplying everything from high-tech components to steel. Plant closures and production outages among Japan's high-tech companies were among the biggest threats to the global supply chain as an estimated fifth of all global technology products are made in Japan. Lean supply chains such as Toyota Corp's and Sony Corp's had to suspend production.

The third aspect of the expected tradeoffs in a sustainable supply chain (3); to do no net harm at a profit for an extended period of time, customer willing. This is a moving target. Customers define the success requisites for any supply chain. Today, shorted product life cycles and faster shifts in customers' tastes and preferences occur due to numerous factors including technological advances, innovation and innovation diffusion rates, and/or domestic and international competition, which usually lead to overcapacity which in turn switches the competition to price cutting and profit erosion. For example, after decades of dominance in the automobile industry, the large family-sedan appears to be well into the decline stage and only a few large cars, such as Ford's Crown Victoria, are being manufactured today. Far removed from the days of Ford's one-size-fits-all automobile, their 
supply chain today envisions cars being made to match an actual customer's taste and budget - and in less than a week. On the sales side, the degree to which sustainability, i.e., doing no harm to the social and natural systems, may alter customer preference negatively or positively depending on the type of benefit consumers most value for the product category in question. For example, in a recent study, Luchs and colleagues (2010) reported that sustainability is not always an asset, even if most consumers care about social and environmental issues. The authors reported that consumers associate higher product ethicality with gentleness-related attributes and lower product ethicality with strengthrelated attributes. As a consequence of these associations, the positive effect of product sustainability on consumer preferences is reduced when strength-related attributes are valued (an example of this product category would be vehicles), sometimes even resulting in preferences for less sustainable product alternatives (i.e., the "sustainability liability."Conversely, when gentleness-related attributes are valued (an example of this product category would be shampoos), sustainability enhances preference.

Clearly, supply chain sustainability is a complex phenomenon that requires developing a strategic fit between a supply chain and a moving target, i.e., supply chain's ever changing success requisites and dynamic operating environment. There has to be a strategic fit between supply chain's supply management capabilities (represented by the additive combinations of its members' capabilities) and supply chain governance and the changing nature of sustainability.

To that end, "What capabilities allow a supply chain to effectively tradeoff the aforementioned sustainability dimensions?" With the complex nature of supply chains and the complexity of the movements of product, services, and information in multiple directions, it would be more parsimonious to focus on one or few of the many supply chain threads. Especially if one is able to point out one of the most impactful threads in terms of supply chain sustainability.

In 2010, the Institute for Supply Management (ISM) estimated that in each supply chain; supply management controls trillions of dollars annually, responsible for and controls $50 \%$ to $70 \%$ of total costs and resources. The Pareto principle (also known as 80/20 rule) applies here- "in any series of elements to be controlled, a selected small factor in terms of the number of elements almost always accounts for a large factor in terms of effort." Supply management has a hold over a significant portion of a supply chain's resources and, thereby, a hold over its projected sustainability or lack thereof, if the supply management thread severs. The Institute for Supply Management ${ }^{\mathrm{TM}}$ (ISM) defines supply management as the identification, acquisition, access, positioning and management of resources and related capabilities the organization needs or potentially needs in the attainment of its strategic objectives. In a given supply chain, supply management determines the capacity to maximizing opportunities and managing risks. Supply management serves to explore business opportunities and implement supply strategies that deliver the most value possible to the organization, its suppliers and customers (ISM, 2010).

Supply management capabilities are a crucial ingredient of every supply chain's sustainability - whether manufacturing or service, large or small. Supply management capabilities allow for improving the bottom-line, capturing interpreting and disseminating relevant supply chain information, increasing efficiency and productivity, supply chain profitability and operational success improving competitive position and customer satisfaction, and building image and social policy. 
Despite interest, supply chain sustainability research efforts are, mostly, fragmented explorations and there is clear dearth of research on the nature of requisite supply management capabilities and governance mechanisms. The delineation between supply management capabilities in achieving the traditional competitive priorities vis. a vis. sustainability is not always clear.

These capabilities allow a supply chain to adapt, survive and grow. Resilience, defined as "the capacity for a supply chain to survive, adapt, and grow in the face of turbulent change" (Pettit et al., 2010). What is the nature of supply chain resilience? What are the requisite supply management capabilities for a supply chain to survive, adapt, and grow? Another more bearing question is "What are the supply management governance mechanisms required to develop and maintain these capabilities?" Governance i.e., structures and processes intended to coordinate and integrate various dimensions of supply management. Governance represents the structures and processes by which societies share power, also shapes individual and collective actions (Young, 1992).

\section{Proposed framework}

\subsection{Supply management capabilities}

In a world of turbulent change, resilience is a key competency since even the most carefully designed supply chain is susceptible to unforeseen events. Many supply chain researchers are beginning to understand the value of the concept of resilience, defined as "the capacity for an enterprise to survive, adapt, and grow in the face of turbulent change" (Pettit et al., 2010). Resilience has been reported as a multifaceted construct with two contrasting aspects of stability-essentially one that focuses on maintaining efficiency of the supply chain (engineering resilience) and one that focuses on maintaining existence of the supply chain (ecological resilience). For the purposes of this study, this study will focus mainly on supply chain ecological resilience.

A central concept in my study, therefore, is ecological resilience which indicates how far the supply chain could be perturbed without shifting to a different regime. Ecological resilience denotes the amount of change a system can undergo and still retain the same controls on structure and function or remain in the same domain of attraction (Walker et al., 2006).

Figure 2 depicts the proposed conceptual model of supply chain ecological resilience; focusing on its supply management antecedents. This study proposes that supply chain ecological resilience is an essential precursor to supply chain sustainability. Strengthening the capacity of a supply chain to ensure ecological resilience is critical to achieving sustainability.

Proposition 1: Supply chain ecological resilience is required to create a sustainable supply chain.

Supply chain ecological resilience is a complex phenomenon that manifests itself in several supply chain members' capabilities. It is proposed that supply chain ecological resilience is based on situation awareness, keystone vulnerabilities access, and adaptive capacity (McManus, 2008) of supply chain members. Situation awareness indicates an understanding and perception of its entire operating environment. It is the ability to look forward for opportunities, identify crises and their consequences accurately and also understand the trigger factors for crises. This will allow supply chains to effectively address sustainability-related; economic, environmental, and social, tradeoffs when needed. For examples, awareness of customer's perceptions of a supply chain's value propositions, i.e., 
strength vs. gentleness in performance attributes provides some guidance for companies in choosing either to include ethical attributes in new products and to promote sustainable products; or if they need to pay special attention to countering the association between sustainability and lower product strength.

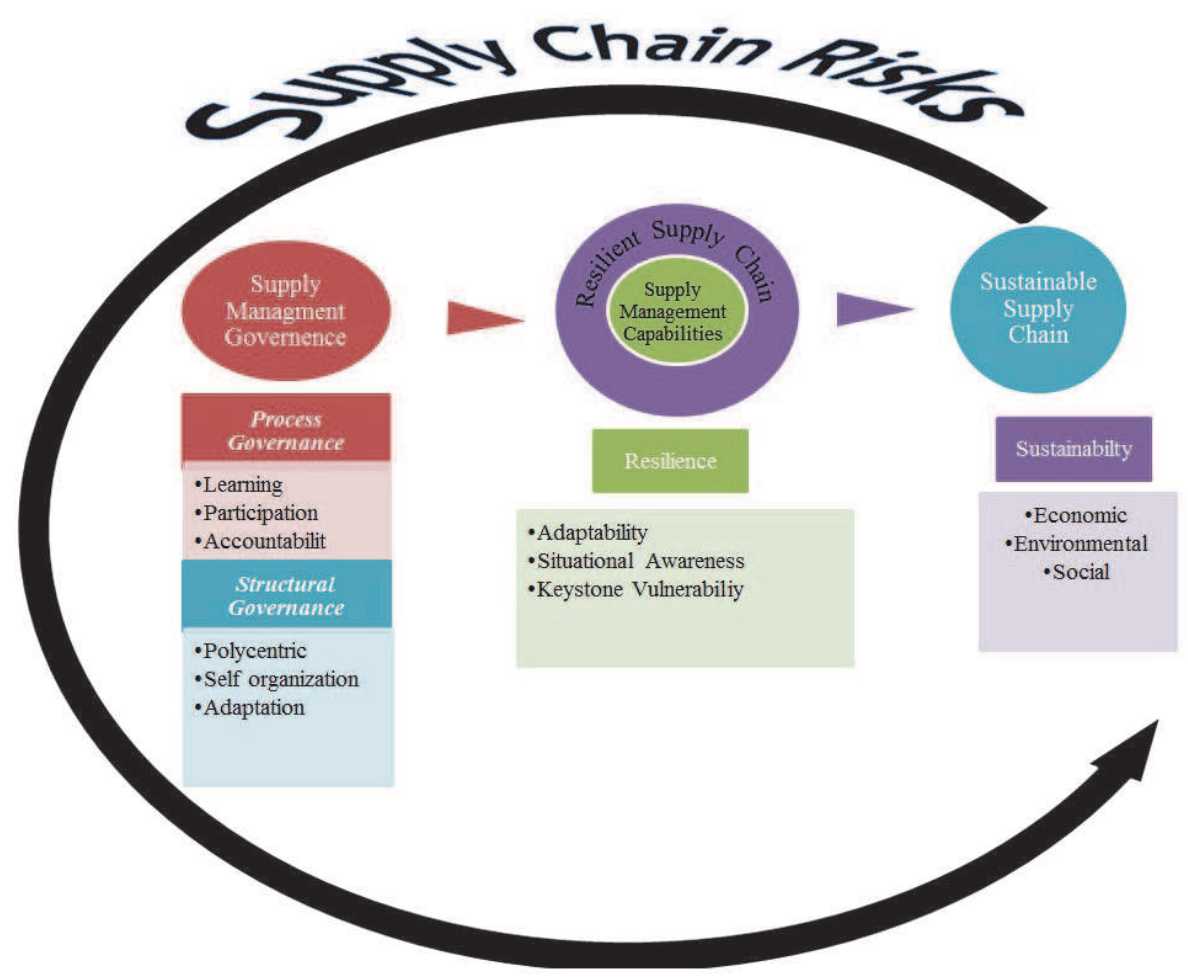

Fig. 2. Proposed Framework of Supply Management Governance Role in Supply Chain Risk Management and Sustainability

Proposition 2a: Supply chain ecological resilience is evidenced by its members' situational awareness of their operating and external environment.

Keystone vulnerabilities define those aspects of a supply chain that have the potential to have significant negative impacts in a crisis situation. This capability addresses the temporal aspect of sustainability and survival goals. The impacts of keystone vulnerabilities may be either catastrophic or insidious. Management of keystone vulnerabilities defines those aspects of an organization, operational and managerial, that have the potential to have significant negative impacts in a crisis situation. It is important for organizations to also have access to the links between supply chain components and the vulnerabilities that may arise from these also. These may include specific tangible organizational components such as: buildings, structures and critical supplies, individual managers, decision makers and subject matter experts. They may also include less tangible components, for example: relationships between key groups internally and externally, communications structures, and perception of the organizational strategic vision. 
Proposition 2b: Supply chain ecological resilience is evidenced by its members' access to keystone vulnerabilities.

Adaptive capacity is a measure of the culture and dynamics of an organization that allow it to make decisions in a timely and appropriate manner both in day-to-day business and also in crises. Adaptive capacity is a measure of the culture that allows it to make decisions in a timely and appropriate manner both in day to day business and also in crises. Adaptive capacity considers aspects of a supply chain such as the leadership and decision making structures, the flow of information and knowledge and the degree of creativity and flexibility that the organization promotes or tolerates. Toyota's capacity to overcome the damage of 2011's tsunami in Japan and the speed of such recovery depends on their leadership and decision making structures, the acquisition, dissemination and retention of information and knowledge, and the degree of creativity and flexibility that the organization promotes or tolerates.

Proposition 2c: Supply chain ecological resilience is evidenced by its members' adaptive capacity.

\subsection{Supply management governance}

In this study, the vehicle to strengthening the capacity of a supply chain to ensure ecological resilience is proposed to be via supply management governance; i.e., structures and processes intended to coordinate and integrate various dimensions of the supply management. Governance represents the structures and processes by which societies share power, also shapes individual and collective actions (Young, 1992). Firms should be deliberate in devising and implementing appropriate supply management governance mechanisms to safeguard against such market imperfections and supply chain uncertainties. Such governance mechanisms make it possible to achieve supply chain ecological resilience, thus enabling the firm to adapt rapidly while retaining coherence even as its supply chain continues to expand. But the question is "which forms of supply management governance are required to achieve supply chain ecological resilience?"

Williamson (2008) points to three styles of supply chain governance that foster sustainability: muscular, benign and credible. Under the muscular approach one of the parties holds the balance of power, and does not hesitate to exercise it. "Muscular buyers not only use their suppliers, but they often 'use up' their suppliers and discard them." The muscular approach to outsourcing of goods and services is "myopic and inefficient." The benign approach is well, too benign because it assumes that cooperation to deal with unforeseen contingencies and achieve mutual gains will always be there. Trust should not necessarily supplant power entirely and indefinitely, Williamson argues, and that is where the credible part comes in. The credible approach to governance is hardheaded (no benign behavior allowed!) but not mean-spirited (as in muscular). In this study, it is proposed that using a credible governance approach in supply management is a precondition to supply chain ecological resilience.

Proposition 3: Deliberate interventions in the form of supply management credible governance determine the extent of supply chain ecological resilience.

Credible supply management governance arises out of the awareness that complex contracts with suppliers and clients are "incomplete and thus pose cooperative adaptation needs" and require the exercise of "feasible foresight." Credible supply management governance maintains supply chain's capacity for renewal in a dynamic environment, provides an ecological buffer that protects the system from the failure as a result of management actions that are taken based upon incomplete understanding, and it allows managers to learn and change. 
Credible supply management structural governance includes polycentric mechanisms, supply management self-organization mechanisms and supply management adaptation mechanisms Supply management polycentric mechanisms are deployable in multilayered institutions and supply chains to improve the fit between knowledge, action, and social-ecological contexts in ways that allow firms and supply chains to respond more adaptively at appropriate levels. Such mechanisms allow access to keystone vulnerabilities and exchange of relevant intelligence among the extended tiers of a supply chain.

Proposition 4a: Managers of sustainable supply chains will employ polycentric mechanisms to improve the fit between knowledge, action, and supply chain contexts in ways that allow firms to respond more adaptively at appropriate levels.

Supply management self-organization mechanisms allow the supply chain to maintain and re-create its identity. Dramatic change has occurred in the last two decades in how supply chains operate. In today's interconnected and information-laden world, supply chain problems increasingly transcend the jurisdictional boundaries of one firm and their specialized functions agencies at all levels. When crises take place self-organizing governance enables the emergence of collaborative institutions in which multiple agencies, and other stakeholders work together to solve problems that affect them. As new vulnerabilities emerge, supply chain they can constituents are expected to self-organize into new networks and sub-networks as required by the situation. Communication and information sharing through technology and access to common data structures enables selforganization mechanisms. The natural evolutionary process for organizations coming together to solve complex problems, i.e., new infrastructure, is based on the relational and structural embeddedness (Bernardes, 2010). The key element in deploying and nurturing this new infrastructure is to design a governance structure where ideas, creativity, and collaboration can thrive. A centralized, top-down governance structure would not have the capacity to adapt quickly to changes in a diverse, technologically dependent entity the supply chain of today.

Proposition 4b: Managers of sustainable supply chains will use self-organization mechanisms that allow the supply chain to maintain and re-create its identity.

Supply management adaptation mechanisms allow the supply chain to get better at pursuing a particular set of management objectives over time and at tackling new objectives when the context changes. With the traditional serialized form of interactions, buyers, suppliers and logistic providers have obstructed views and limited visibility into the activities within the supply chain. Adaptation mechanisms enable full visibility of the supply chain, which allows transforming efforts and strategy to new goals when needed. Proposition 4c: Managers of sustainable supply chains will use adaptation mechanisms that allow the supply chain to get better at pursuing a particular set of management objectives over time and at tackling new objectives when the context changes.

On the other hand, credible supply management processes governance involves mechanisms that facilitate learning, participation of supply chain constituents, and a sense of accountability.

Learning mechanisms allow for acceptance of the inevitability of change and experimentation. From more influential to less, social mechanisms of governance, hostages and behavioral control should favor knowledge sharing, learning and performance in supply chains. Learning governance mechanisms allow for tacit knowledge generational transfers from senior to junior employees. It allows institutions to train new employees to 
support the infrastructure of the supply chain, and it allows operational efficiencies to emerge as the learning curve is descended.

Proposition 4d: Managers of sustainable supply chains will employ mechanisms that facilitate learning and acceptance of the inevitability of change and experimentation.

Participation of supply chain constituents is based on mechanism designated to build trust and deliberation among supply chain constituents, which, in turn, leads to the shared understanding needed to mobilize and self-organize. If performance on either dimension of sustainability (economic such as responsiveness or efficiency or environmental, or social) is less than desirable, the supply chain and/or its participant firms must create or alter strategies in order to improve performance. The challenge in and the success of altering strategies stems from the capacity to identifying, collecting, disseminating, and utilizing relevant intelligence into the strategy formation process. This reflects a need for multilayered inter-organizational sharing of knowledge. Particularly, when supply chain problems involve multiple supply chain participants and their respective knowledge sets, establishing the need for sharing and some form of collective action becomes an imperative aspect of process governance.

Proposition 4e: Managers of sustainable supply chains will foster participation of supply chain constituents to build trust and deliberation among supply chain constituents, which, in turn, leads to the shared understanding needed to mobilize and self-organize.

A sense of accountability governance pursues just distributions of benefits and involuntary risks enhance the adaptive capacity of vulnerable groups and the supply chain as a whole. The importance of accountability in global complex supply chains has never been more evident than today, following the debacles of some large firms and corporate financial scandals. Resilient supply chains, being situationally aware and adaptive, instill accountability governance today to correspond to external regulations as well as pressures from other stakeholders. Accountability is a key element as for supply chain governance, fortifying the latter in such a way that it provides a transparent template for managing keystone vulnerabilities, i.e., governing critical decisions, procedures, and activities. Today's supply chain's environment is a richer yet more complex than ever. Accountability governance deals with a larger number of cross-border stakeholders whose interests are frequently contradictory, facing more difficulties in controlling decision-makers in globally dispersed yet differentiated supply chains, and encounters greater pressure in the balance between accountability governance and efficiency.

Proposition 4f: Managers of sustainable supply chains will engender a sense of accountability to pursue just distributions of benefits and involuntary risks enhance the adaptive capacity of vulnerable groups and the supply chain as a whole.

\section{Conclusions}

This study proposes that sustainable supply chains will employ polycentric mechanisms to improve the fit between knowledge, action, and supply chain contexts in ways that allow firms to respond more adaptively at appropriate levels. They are expected to deploy selforganization mechanisms that allow the supply chain to maintain and re-create its identity and adaptation mechanisms that allow the supply chain to get better at pursuing a particular set of management objectives over time and at tackling new objectives when the context changes. 
This form of supply management processes governance involves mechanisms that facilitate learning (acceptance of the inevitability of change and experimentation); participation of supply chain constituents (building trust and deliberation among supply chain constituents, which, in turn, leads to the shared understanding needed to mobilize and self-organize); and a sense of accountability (pursue just distributions of benefits and involuntary risks enhance the adaptive capacity of vulnerable groups and the supply chain as a whole).

\section{Managerial implications}

One of the first reactions supply managers may have in dealing with risk is to grab for greater control (Guinepero and Eltantawy, 2004). This usually leads to increased vulnerabilities to economic risks. Therefore, it is up to the top management and supply managers to instill the governance mechanisms that aid supply chains to adapt and transform in correspondence to vulnerabilities. The proposed framework has great potential for providing management insight into their strengths, weaknesses, and priorities. Firms must first identify their current resources and strengths - what they can do more effectively than their rivals. First, by identifying their external and internal supply chain vulnerabilities. To manage supply chain risks and develop the resilience needed to compete today, supply professionals need to coordinate the relationships in the supply chain and increase the flow of information and communication efforts. Thus, hiring and developing employees is the key to managing risks in supply chain. It is equally important as well that top management allow purchasing the freedom to pursue potentially risky endeavors as long as appropriate plans to manage risks are developed (Giunipero and Eltantawy, 2010).

This study aims at crystallizing the requisite SM governance and capabilities to supply chain sustainability. These capabilities are relevant and valuable when supply chains and their constituent members are risk aware and receptive to external stakeholder pressures. Early movers in the field of resilient and sustainable supply chains are expected to reap competitive benefits to a notable extent as a result of resource accumulation and learning processes over time.

Firms need to identify their highly rated capabilities and a detailed stock of information on their strengths. Deliberate interventions in the form of supply management credible governance determine the extent of supply chain ecological resilience. Managers of sustainable supply chains will employ polycentric mechanisms to improve the fit between knowledge, action, and supply chain contexts in ways that allow firms to respond more adaptively at appropriate levels. They are expected to deploy self-organization mechanisms that allow the supply chain to maintain and re-create its identity and adaptation mechanisms that allow the supply chain to get better at pursuing a particular set of management objectives over time and at tackling new objectives when the context changes.

The framework provides managerial guidance for setting priorities to create a governance mechanisms and strategy for improving supply chain resilience and sustainability. However, resilience is not simply a matter of strengths, but it is the balance between capabilities and vulnerabilities that creates a firm's true competitive advantage (Pettit et al., 2010). Therefore, periodic assessment of the supply management governance and capabilities as well as resilience of the supply chain is necessary. 


\section{Reference}

Bernardes, E.S. 2010. The effect of supply management on aspects of social capital and the impact on performance. Journal of Supply Chain Management. 46(1), 45-66.

Carter, C. R. and Rogers. D.S. 2008. A framework of sustainable supply chain management: moving toward new theory. International Journal of Physical Distribution $\mathcal{E}$ Logistics Management, 38(5), 360-387.

Cash, D. W., Adger, W., Berkes, F., Garden, P., Lebel, L., Olsson, P., Pritchard, L., and Young, O. 2006. Scale and cross-scale dynamics: governance and information in a multilevel world. Ecology and Society 11(2): 8. [online] URL:

http://www.ecologyandsociety.org/vol11/iss2/art8/

Chin, W. The partial least squares for structural equation modeling In Marcoulides, G.A. (Ed.). Modern methods for business research. Lawrence Erlbaum,1998, Mahwah, NJ.

Cohen, B. and Winn, M.I. 2007. Market imperfections, opportunity and sustainable entrepreneurship. Journal of Business Venturing, 22(1), 29-49.

Cousins, P. D. 2005. The alignment of appropriate firm and supply strategies for competitive advantage. International Journal of Operations $\mathcal{E}$ Production Management, 25(5/6), 403430.

Craighead, C. W., Blackhurst, J., Rungtusanatham, J. M. and Handfield, R. B. 2007. The severity of supply chain disruptions: Design characteristics and mitigation capabilities. Decision Sciences, 38(1), 131-156.

Fiksel, J. 2003. Designing resilient, sustainable systems. Environmental Science E Technology, 37(23), 5330-5339.

Folke, C. 2006. Resilience, vulnerability, and adaptation: A cross-cutting theme of the international human dimensions programme on global environmental change. Global Environmental Change, 16(3), 253-267.

Frankel, R., Bolumole, Y. A., Eltantawy, R. A., Paulraj, A. and Gundlach, G. T. 2008. The domain and scope of SCM's foundational disciplines: Insights and issues to advance research. Journal of Business Logistics, 29(1), 1-31.

Giunipero, L.C. and Eltantawy, R.A. 2004. Securing the upstream supply chain: a risk management approach. International Journal of Physical Distribution $\mathcal{E}$ Logistics Management, 34(9), 698 - 713.

Gunderson, L. H., and Holling, C. S. editors. Panarchy: understanding transformations in human and natural systems. Island Press, 2002, Washington, D.C.

Hair, J.F., Anderson, R.E., Tatham, R.L., and Black, W.C. Multivariate data analysis. 5th ed. Prentice-Hall, 1998, New Jersey.

Jeffers, P. I. 2010. Embracing sustainability; Information technology and the strategic leveraging of operations in third-party logistics. International Journal of Operations $\mathcal{E}$ Production Management. 30(3), 260-287.

Jick, T.D., 1979. Mixing qualitative and quantitative methods: triangulation in action. Administrative Science Quarterly, 24 (4), 602-611.

Ketchen, D.J. and Hult, G.T. 2011. Building theory about supply chain management: Some Tools from the organizational sciences. Forthcoming: Journal of Supply Chain Management, 47(2).

Kleindorfer, PR., Singhal, K. and van Wassenhove, L.N.2005. Sustainable operations management. Production and Operations Management, 14(4), 482492. 
Krause, D. R, Vachon, S., and Klassen, R. D. 2009. Special topic forum on sustainable supply chain management: Introduction and reflections on the role of purchasing management. Journal of Supply Chain Management, 45(4), 18-25.

Luchs, M.G., Naylor, R. W., Irwin, J. R., and Raghunathan, R. 2010. The Sustainability Liability: Potential Negative Effects of Ethicality on Product Preference. Journal of Marketing, 74 (September), 18-31.

Menachof, D. A., Gibson, B. J., Hanna, J.B., and Whiteing, A. E. 2009. An analysis of the value of supply chain management periodicals. International Journal of Physical Distribution $\mathcal{E}$ Logistics Management, 39(2), 145-166.

Mann, H., Kumar, U., Kumar, V., Jit, I., and Mann, S. 2010. Drivers of sustainable supply chain Management. IUP Journal of Operations Management, 9(4), 52-63.

McManus, S.T. Organizational resilience in New Zealand. Doctoral thesis, University of Canterbury, 2008, New Zealand.

Pagell, M. and $\mathrm{Wu}, \mathrm{Z}$. 2009. Building a more complete theory of sustainable supply chain management using case studies o 10 exemplars. Journal of Supply Chain Management, 45(2), 37-56.

Pettit, T.J., Fiksel, J., and Croxton, K.L. 2010.Ensuring supply chain resilience: Development of a conceptual framework. Journal of Business Logistics, 31(1), 1- 22.

Pullman, M. E., Maloni, M.J., and Carter, C.R. 2009. Food for thought: Social versus environmental sustainability practices and performance outcomes. Journal of Supply Chain Management, 45(4), 38-54.

Reuter, C., Kai, F., Evi, H., and Constantin, B. 2010. Sustainable global supplier management: The role of dynamic capabilities in achieving competitive advantage. Journal of Supply Chain Management, 46(2), 45-63.

Sheffi, Y. 2005. The Resilient Enterprise: Overcoming Vulnerability for Competitive Advantage, Cambridge, MA: MIT Press.

Skilton, P.F. 2011. Getting the reader to "I get it!": Clarification, differentiation and illustration. Forthcoming: Journal of Supply Chain Management (2011), 47(2).

Svensson, G. 2002. Dyadic vulnerability in companies' inbound and outbound logistics flows. International Journal of Logistics and Research Applications, 5(1), 13-44. 2007. Aspects of sustainable supply chain management (SSCM): conceptual framework and empirical example. Supply Chain Management: An International Journal, 12(4), $262-266$.

Terpend, R., Tyler, B.B., Krause, D., R., and Handfield, R.B. 2008. Buyer-supplier relationships: derived value over two decades. Journal of Supply Chain Management, 44 (2), 28-55.

Walker, B. H., Anderies, J. M., Kinzig, A. P., and Ryan, P. 2006. Exploring resilience in socialecological systems through comparative studies and theory development: introduction to the special issue. Ecology and Society 11(1), [online] URL: http://www.ecologyandsociety.org/vol11/iss1/art12/.

Williamson, O. E. 2008. Outsourcing: Transaction cost economics and supply chain management. Journal of Supply Chain Management, 44(2), 5-16.

Young, O. R. The effectiveness of international institutions: hard cases and critical variables. Pages 160-194 in Rosenau, J. N. and Czempiel, E.-O. editors. Governance without government: order and change in world politics. Cambridge University Press, 1992, Cambridge, UK. 
Zsidisin, G.A. 2003. A grounded definition of supply risk. Journal of Purchasing and Supply Management, 9(5/6), 217-224.

CSCMP (2010). Retrieved from: URL: www.cscmp.org. This definition was posted at the CLM homepage (www.clml.org). and presented at, the 1998 Council of Logistics Management Conference, Anaheim, CA.ISM (2010). Retrieved from: URL: http://www.ism.ws/tools/content.cfm?itemnumber $=4468$ 


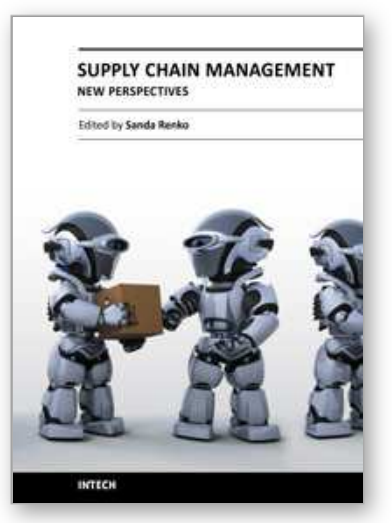

\author{
Supply Chain Management - New Perspectives \\ Edited by Prof. Sanda Renko
}

ISBN 978-953-307-633-1

Hard cover, 770 pages

Publisher InTech

Published online 29, August, 2011

Published in print edition August, 2011

Over the past few decades the rapid spread of information and knowledge, the increasing expectations of customers and stakeholders, intensified competition, and searching for superior performance and low costs at the same time have made supply chain a critical management area. Since supply chain is the network of organizations that are involved in moving materials, documents and information through on their journey from initial suppliers to final customers, it encompasses a number of key flows: physical flow of materials, flows of information, and tangible and intangible resources which enable supply chain members to operate effectively. This book gives an up-to-date view of supply chain, emphasizing current trends and developments in the area of supply chain management.

\title{
How to reference
}

In order to correctly reference this scholarly work, feel free to copy and paste the following:

Reham Eltantawy (2011). Supply Management Governance Role in Supply Chain Risk Management and Sustainability, Supply Chain Management - New Perspectives, Prof. Sanda Renko (Ed.), ISBN: 978-953-307633-1, InTech, Available from: http://www.intechopen.com/books/supply-chain-management-newperspectives/supply-management-governance-role-in-supply-chain-risk-management-and-sustainability

\section{INTECH}

open science | open minds

\section{InTech Europe}

University Campus STeP Ri

Slavka Krautzeka 83/A

51000 Rijeka, Croatia

Phone: +385 (51) 770447

Fax: +385 (51) 686166

www.intechopen.com

\section{InTech China}

Unit 405, Office Block, Hotel Equatorial Shanghai

No.65, Yan An Road (West), Shanghai, 200040, China

中国上海市延安西路65号上海国际贵都大饭店办公楼 405 单元

Phone: +86-21-62489820

Fax: +86-21-62489821 
(C) 2011 The Author(s). Licensee IntechOpen. This chapter is distributed under the terms of the Creative Commons Attribution-NonCommercialShareAlike-3.0 License, which permits use, distribution and reproduction for non-commercial purposes, provided the original is properly cited and derivative works building on this content are distributed under the same license. 